\title{
Küresel Tüketici Kültürüyle Özdeşleşmenin Hedonik ve Faydacı Alışveriş Değeri Üzerindeki Etkisi
}

The Impact of Self-Identification with Global Consumer Culture on Hedonic and Utilitarian Shopping Value

\author{
Murat ARSLANDERE ${ }^{1}$
}

Araştırma Makalesi / Research Article

Geliş Tarihi / Received: 25.01.2021

Kabul Tarihi / Accepted: 27.03.2021

Doi: 10.48146/odusobiad.943860

Atıf/Citation: Arslandere, M., (2021). "Küresel Tüketici Kültürüyle Özdeşleşmenin Hedonik ve Faydacl Alışveriş Değeri Üzerindeki Etkisi" ODÜSOBİAD 11(2), 699-714, doi: 10.48146/odusobiad.943860

\section{$\ddot{0} z$}

Özellikle son yıllarda teknolojinin gelişmesi, lojistik ve iletişim imkânlarının artması, dünya genelinde insanlar arasında etkileşimin artması ortak bir tüketim kültürü olușmasına ve bu doğrultuda küresel markalara talebin artmasına sebebiyet vermiştir. Sözkonusu küresel kültürü yüksek seviyede benimseyenler küresel tüketici kültürüyle özdeşlemiş ve bir nevi yașam tarzı haline getirmişlerdir. Genel itibariyle bütün tüketim kültürlerinde tüketiciler ise alışverişleri esnasında rasyonel ve haz odaklı olabilmektedirler. Hedonik alışveriş değeri tüketicinin alışveriş deneyiminin duyusal, arzu ve haz ile ilgili yönlerinden alınan değerler ile ilgiliyken, faydacı alıșveriș değeri ise tüketicinin rasyonel beklentileri ile ilgili olmaktadır. Bu çalıșmada "küresel tüketici kültürüyle özdeşleşmenin" (i)hedonik alışveriş değeri ve (ii)faydacı alış veriş değeri üzerindeki eşzamanlı etkisi incelenmiştir. Bu amaçla 302 küresel marka tüketicisine anket uygulanmış, Kısmi En Küçük Kareler yöntemi ile yapısal eşitlik modelinin tahmini (PLS-SEM) SmartPLS 3.0 yazılımı kullanılarak istatistiksel olarak analiz edilmiştir. Sonuç olarak küresel tüketici kültürüyle özdeşlemenin, hedonik alışveriş değerini güçlü ve pozitif yönde, faydacı alışveriş değerini ise pozitif yönde etkilediği tespit edilmiștir.

Anahtar Kelimeler: Küresel Tüketici Kültürüyle Özdeșleşme, Hedonik Alşveriş Değeri, Faydacı Alışveriş Değeri, Küresel Tüketici Kültürü, Küresel Tüketici Kültürüyle Kültürleşme

\begin{abstract}
Especially in recent years, the development of technology, the increase in logistics and communication opportunities has led to the formation of a common consumption culture by increasing interaction among people around the world, and in this direction, the demand for global brands has increased. Those who adopt the aforementioned global culture at a high level have identified with the global consumer culture and have made it a kind of lifestyle. In general, in all consumption cultures, consumers can be rational and pleasure-oriented during their shopping. While the hedonic shopping value is related to the values taken from the sensory, desire and pleasure-related aspects of the consumer's shopping experience, the utilitarian shopping value is related to the rational expectations of the consumer. In this study, the simultaneous effect of "self-identification with global consumer culture" on (i)hedonic shopping value and (ii)utilitarian shopping value was examined. For this purpose, a questionnaire was applied to 302 global brand consumers, and the estimation of the structural equation model
\end{abstract}

1 Dr. Öğr. Üyesi, Karamanoğlu Mehmetbey Üniversitesi, Uygulamalı Bilimler Yüksekokulu, E-Posta: muratarslandere01@gmail.com, ORCID: 0000-0002-0069-9275 
(PLS-SEM) with the Partial Least Squares method was statistically analyzed using SmartPLS 3.0 software. As a result, it was determined that self-identification with global consumer culture has a strong and positive effect on the hedonic shopping value and has a positive effect on the utilitarian shopping value.

Keywords: Self-Identification with Global Consumer Culture, Hedonic Shopping Value, Utilitarian Shopping Value, Global Consumer Culture, Acculturation to the Global Consumer Culture

\section{Giriş}

"Dünyanın tek bir yer olarak kristalleşmesi" olarak tanımlanan küreselleşme, giderek birbirine bağımlı hale gelen bir dünya-uzayını tasvir etmektedir. Küreselleşmenin ekonomik ve politik sonuçları tartışılmaz boyuttadır (Cleveland vd., 2015). Küreselleşen dünyada küresel markaların tüketimdeki önemi yadsınamaz. Küresel markaların tüketimi, bu tüketicilerin kozmopolit, bilgili ve / veya modern "dünya vatandaşları" olarak tanımlanmasına yardımcı olmaktadır. Bu tür tüketiciler, ortak tüketim faaliyetleri, ürün kategorileri ve küresel markalar dahil olmak üzere, dünya çapında paylaşılan ortak "tüketimle ilgili semboller" kümesini beğeniyle karşılamaktadır (Alden vd., 1999).Küresel tüketici kültürü "karmaşık, örtüşen, ayrık bir düzen" (Appadurai 1990: 296) ve "tek bir ülkeyle ilişkili olmayan, daha ziyade genellikle uluslararası ve bireysel ulusal kültürleri aşan daha büyük bir grupla ilişkili bir kültürel varlıktır" (Cleveland vd., 2015). 2000’li yılların başında orataya çlkan "küresel tüketici kültürüne uyum"veya "küresel tüketici kültürüyle kültürleşme" kavramı ise; bireylerin yeni ortaya çıkan ve belirli bir vatanı olmayan bir küresel tüketici kültürünün özelliği olan bilgi, beceri ve davranışları nasıl edindiklerini ele almaktadır (Cleveland ve Laroche, 2007). Sözkonusu kavram ile birlikte Cleveland ve Laroche(2007)tarafından geliştirilen ölçek, küresel tüketiciliğe adaptasyonla ilgili tüketici zihniyetlerini ölçmek için ilk girişim olmuştur (Durvasula ve Lysonski, 2015). Bu kavram; kozmopolitizm, çok uluslu/küresel şirketlerin pazarlama faaliyetlerine maruz kalma, İngiliz dilinin kullanımına maruz kalma, sosyal etkileşimler (seyahat, göç, yabancılarla iletişim), küresel / yabancı medyaya maruz kalma, küresel tüketim kültürünü taklit etme açıklı̆̆ı (veya arzusu), küresel tüketici kültürüyle özdeşleşme olarak yedi boyut altında ele alınmaktadır. Bu boyutların zirvesinde olan, küresel tüketici kültürüyle bütünleşmeyi ortaya koyan, "küresel tüketici kültürüyle özdeşleşme” boyutudur. Küresel tüketici kültürüyle özdeşleşme, bir bireyin küresel tüketici hareketini nasıl giyindikleri, okudukları ve uluslararası markalarla nasıl etkileşime girdikleri açısından yansıtma arzusunu yansıtır (Cleveland ve Laroche, 2007).Küresel markaların takdir edilmesi küresel tüketici kültürüyle özdeşleşme ile ilişkilidir ve tüketicilerin küresel vatandaşlık duygularını beslemektedir (Cleveland ve Laroche, 2007). Öte yandan tüketim davranışının, bireyin öncelikle zorunlu ihtiyaçlarını karşılaması ile ortaya çıktığı ifade edilebilse de, sonrasında tüketim, bireyin kendisini ifade etmesine olanak veren kültürel bir olgu halini alarak prestij ve statü göstergelerine dönüşmüştür. Bu dönüşüm beraberinde, hem psikolojik hem fonksiyonel beklentileri getirmiştir. Bir zamanlar tek amaç ürün ve hizmetleri hemen tüketmek iken; sonraki süreçlerde ürün ve hizmetlerin tüketimleri yalnızca bir amaç olmanın sınırlarını aşarak, bireylerin davranışlarının da önemli bir parçası haline gelmişlerdir (Storey, 2000:136).Uzun yıllardır literatürde incelenen tüketim davranışları üzerindeki güçlü etkileri ortaya konulan hedonik ve faydacı alış veriş değeri, tüketicilerin alışveriş değerlerini açıklayan iki önemli kavram olarak karşımıza çıkmaktadırlar. Dolayısıyla bu kavramların küresel tüketici kültürüyle özdeşleşmeyle de etkileşim halinde olmalarının dakuvvetle muhtemel olduğu düşünülmektedir.

Literatürde küresel tüketici kültürüyle kültürleşmenin(bütün boyutlar) tüketici etnosentrizmi ve materyalizm ile ilişkisini araştıran (Lysonski ve Durvasula, 2013; Cleveland vd., 2015), küresel tüketici kültürüyle kültürleşmenin (beş boyutu) algllanan küresel marka değerine etkisini araştıran (Frank ve Watchravesringkan, 2016), farklılık analizi yapılarak küresel tüketici kültürüyle kültürleşmenin diğer boyutlarıyla birlikte küresel tüketici kültürüyle özdeşleşme seviyelerinin kuşaklar arası farklılığının test edildiği (Carpenter vd., 2012), küresel/yabancı medyaya maruz kalma, çok uluslu/küresel şirketlerin pazarlama faaliyetlerine maruz kalma ve demografik değişkenlerin, küresel tüketici kültürüyle özdeşleşmeye etkisini araştıran (Ural, 2008), küresel 
tüketici kültürüyle kültürleșmenin tüketim alışkanlıkları üzerindeki etkisi araștıran (Yapraklı ve Keser, 2016)çalışmalar bulunmaktadır. Ayrıcaküresel tüketici kültürüyle kültürleşmenin diğer boyutlarının ele alınmayarak bu çalışmada olduğu gibi sadece küresel tüketici kültürüyle özdeşleşme boyuntunun tek değissken olarak ele alındığı; materyalizm, kozmopolitanizm ve tüketici etnosentrizminin, küresel tüketici kültürüyle özdeşleşmeye etkisi ile küresel tüketici kültürüyle özdeşleşmenin global markalı ürünleri satın alma niyetine etkisini araştıran (Okazaki vd., 2019), global marka bilgisinin küresel tüketici kültürüyle özdeşleşmeye, küresel tüketici kültürüyle özdeșleșmenin iseglobal marka sadakatine ektisini araștıran (Suprawan, 2018) çalışmalar da bulunmaktadır. Görüleceği üzere literatürde küresel tüketici kültürüyle özdeşleşme üzerine sınırlı sayıda çalışma bulunmaktadır. Bu duruma yeni bir kavram olmasının sebep olduğu tahmin edilmektedir. Bu çalışmada küresel tüketici kültürüyle özdeşleșmenin hedonik ve faydacı alışveriş değerinine eşzamanlıetkisinin incelenmesiylelitereatüre orjinal katkı sağlanması amaçlanmıștır.

\section{Literatür Taraması ve Hipotez Geliștirme}

Küreselleşme, tüm dünyadaki tüketicilerin ortak yaşam tarzlarını tanıtan bir kavramı temsil etmektedir. Sosyokültürel bir perspektiften (Tomlinson, 1999) küreselleşme, gezegendeki sosyal etkileşimleri genişleten, derinleștiren ve hızlandıran "karmaşık bağlantı" olarak değerlendirilir. İnternet, mobil iletişim ve sosyal medya gibi argümanlar bu bağlantıyı mümkün kılar. Bu bağlantılar, dünyadaki herkesin yaşamını etkilemektedir (Özsomer, 2019).Küreselleşme, değişken yapısı olan bu talebi hem tüketici pazarlarının özelliklerini hem de tüketicilerin satın alma davranışlarını değiştirerek etkilemektedir. Uluslararası lojistik olanaklarının artması, iletişim teknolojilerinin sunduğu imkânların mesafeleri yok etmesi, pazarlama faaliyetleri ve bunlar arasında önemli yere sahip olan reklamlar ile küresel tüketim kültürü mümkün hale gelmiștir. Ekonomiler ve kültürler arasındaki sınırlar, küreselleşme karşısında etkilerini yitirmektedirler (Ger, 1999). Son yıllarda, teknolojik gelişmeler maliyetleri düşürmüş ve uluslararası seyahat firsatları genişlerken, küresel telekomünikasyon pazarlama mesajlarının küresel bir izleyici kitlesine ulaşmasına izin vermşitir. Medya, pazarlama ve turizm "kültürel aracılar" olarak işlev görmektedir. Küreselleşmenin bu güçleri, dünyadaki pek çok toplumu amansız bir şekilde bir araya getirmekte ve tüketiciler artık diğer kültürlerle tanışmak için kendi ülkelerinin ötesine seyahat etmek zorunda kalmamaktadırlar (Cleveland, 2018). Ortaya çıkan küresel tüketim kültürü, malların, paranın, bilginin, insanların ve hizmetlerin akışıyla bağlantılıdır. Küresel medyaya ve markalara maruz kalmak, tartışmalı bir şekilde tüketicilerin zihniyetini değiştirmiş ve popüler markalar, modern yaşam tarzları ve tüketim tercihleri hakkında bilinçlenmeye neden olmuştur. Bazı araștırmacılar, böyle bir küreselleşmenin ekonominin ötesine geçen kültürel bir karşılıklı bağımlılık ve birbirine bağlılık ortaya çıkardı̆̆ını iddia etmektedir (Lysonski ve Durvasula, 2013). Ger ve Belk (1996), küresel kültürün oluşmasının büyük ölçüde, devlet tarafından kontrol edilen ekonomilerin özelleștirilmesine ve pazarlanmasına ve artan miktarda yabancı mal ve medya ihracatına bağlı olduğunu iddia etmişlerdir. Küreselleşme ile bir anlamda homojenleșen pazarlarda rekabet eden çok uluslu işletmeler pazarlamada uyguladıkları standardizasyon stratejileri ile daha geniş pazarlara ulaşabilmekte ya da mevcut pazarlarındaki karlılıklarını arttırabilmektedirler (Schuh, 2000). Sonuçta pazarlamada uygulanan standardizasyon stratejileri, üretilen ürün kalitesini yükseltmek ve bunun yanında maliyetleri düşürmek yoluyla dış kaynaklardan daha verimli yararlanabilmeye (Keegan ve Green, 2003) ve üretimde sürecinde daha etkin olabilmeye (Levitt, 1983) imkân vermektedir. Bu faydalardan yararlanmak isteyen şirketlerin de küresel bir tüketici kültürünü özellikle desteklemeleri beklenebilir. Alden vd. (1999)küresel tüketici kültürünü, segment üyeleri için anlamlı olan tüketimle ilgili paylaşılan semboller (ürün kategorileri, markalar, tüketim faaliyetleri vb.) olarak tanımlamaktadır. Küresel tüketici kültürü, bazı bilim adamları tarafından öngörüldüğü gibi homojenleşmeyi temsil etmez; daha ziyade, ağırlıklı olarak Batı ve Asya gelişmiş ülkelerinden (örneğin fast food olarak hamburger ve suşi) tüketim işaretlerinin ve davranışlarının küresel yayılımını yansitır (Akaka ve Alden, 2010). 
"Küresel tüketici kültürüyle özdeșleme" veya başka bir deyişle "küresel tüketici kültürüyle kendini tanımlama"; küresel tüketici kültürüyle kendilerine atfedilen üyeliklerini kabul eden veya bunu bir kesin bir kimlik nevinde açıkça benimseyen bireylerle ilgilidir (Cleveland ve Laroche, 2007:255). Kendini tanımlama kavramı, "bir bireyin bir sosyal gruba (veya gruplara) üyeliğine ilişkin bilgisinden ve bu üyeliğe atfedilen duygusal önemden kaynaklanan benlik kavramı" olarak tanımlanan sosyal kimlik teorisinden (SIT) türetilmiştir. Bu kavram genellikle, insanların kendilerini bir "grup dışı" yerine bir "grubun" parçası olarak nasıl gördüklerinin tepkisini açıklar. Kendini bir grubun parçası olarak görmek, grubun içini kayırmaya ve dış gruba karşı ayrımcıllğa yol açar (TajfelveTurner 1986). Sosyal kimlik teorisiyle uyumlu olarak, küresel tüketici kültürüyle ile özdeşleşme, küresel pazar segmentine yönelik salt ilgi veya arzunun ötesine geçer. Düşünme kalıplarını etkileyerek, dar görüşlülükten daha küresel bir sosyal kimliğe sahip olan birey, hayatını "küresel tüketici kültürü"ne özgü yaşam tarzlarına ve inanç sistemlerine göre daha çok, geleneksel kültürel anlatıya göre daha az yaşar (Cleveland vd., 2015). Küresel tüketici kültürüyle özdeşleme; kişinin küresel tüketici kültürüyle kültürleşme düzeyinin kişisel öz değerlendirmesini yansıtmaktadır(Frank ve Watchravesringkan, 2016). Küresel tüketici kültürü ile özdeşleşme, tüketicilerin küresel tüketici topluluğunun bir parçası olduklarını hissetme derecesini gösterir. Bazı tüketiciler, küresel tüketim kültürünü taklit etmekle daha çok ilgilenmekte ve bu tutkuyu tatmin etmelerini sağlayan ürünleri seçmektedirler. Nitekim rol modelleri sadece yerel değil, "küresel sahnede" olanlardır. Müzik grupları ve TV programları, nasıl "küresel tüketici" olunacağına dair yön vermektedir (Lysonski ve Durvasula, 2013). Tüketicilerin küresel tüketici kültürüyle özdeșleşmeleri, kozmopolit eğilimlerin doğal bir sonucu olmayan tüketici yaşam tarzlarına ve inanç sistemlerine atıfta bulunur. Aksine, doğası gereği küresel olan bir sosyal kimliği kapsayacak șekilde genişlerler (Cleveland vd., 2015). Daha ayrıntılı olarak açıklamak gerekirse, küresel tüketici kültürüyle özdeşleşen tüketiciler, kendilerini dünyanın her yerindeki tüketicilerle benzer moda zevklerine sahip olarak görme eğilimindedir ve yerel markalardan daha çok uluslararası markaları tercih edeceklerdir (Suprawan, 2018). Daha önce de belirtildiği gibi, insanlar seyahat, kitle iletişim araçları ve küresel reklamcılık yoluyla çeşitli yabancı kültürel unsurlara maruz kalmaktadır. Sonuç olarak, insanlar belirli yaşam tarzları ve inanç sistemleriyle ne ölçüde özdeşleşmek istediklerini seçmekte özgürdürler (Ogden, 2002) ve bu da düşünme ve davranış kalıplarını etkilemektedir. Bu seçim özgürlüğünün erişilebilirlik, gelir, eğitim ve maruz kalma gibi çeşitli bireysel faktörlere bağlı olduğunu belirtmek önemlidir. Bir bireyin kendini küresel tüketici kültürüyle özdeșleștirmesi, küresel segmentin bir parçası olma ilgisinin veya arzusunun ötesine geçmesine izin verir ve aslında bireyin küresel tüketici kültürü tarafından ortaya çıkan değerlere göre davranmasına yol açar (ör: aktif olarak uluslararasıürünleri satın alma ve küresel bir tüketici olma arayışı) (Sobol, 2008).

Genel itibariyle ister yerel olsun ister küresel olsun, bütün tüketim kültürlerinde tüketimi şekillendiren temel faktörler arasında istek, arzu ve ihtiyaç üçlüsü bulunsa da, özellikle geleneksel toplumlarda gerçekleșen tüketim, çoğunlukla ihtiyaçla sınırlandırılmış ve rasyonelliğin etkili olduğu faydacı değerlerle ilgilidir. Bu tür geleneksel toplum yapılarında ihtiyaçtan fazlasını tüketmek kabul görmezken, modern toplumlarda ise bu bakış açısının yerini, sınırsız arzuların tüketimin temel faktörleri arasında ağırlık kazandığı hedonik (haz odaklı) bir yapının almakta olduğu ifade edilebilir (Özcan, 2007). Tüketiciler hedonik değerlerle hareket ettiklerinde ürün ya da hizmetle ilgili arzuları, zevk öngörüsü, duygusal durumları ya da ürünün estetik özellikleri ön planda olabilmektedir. Böylelikle tüketiciler tüketim faaliyetinde bulundukları zaman dilimlerinde sorunlarından uzaklaşabilmekte ya da kendilerini daha iyi hissedecekleri hayali bir gerçekliği alışveriş yaparak yașayabilmektedirler (Enginkaya ve Ozansoy, 2010: 143; Aydın, 2010: 439). Diğer yandan tüketiciler faydacı değerler kapsamında, satın alacakları ürün ya da hizmetlerin nesnel ve fonksiyonel özelliklerine önem vermektedirler (Enginkaya ve Ozansoy, 2010: 143). Carpenter vd. (2005)'e görehedonik değerler duygusal ve psikolojik deneyimlerden meydana gelmektedir. Buna karşıllk, faydacı değer ise, rasyonel bir tutumla faydacı yanlar gözetilmesi olarak ifade edilebilmektedir. Faydacı değer, tüketicinin tatmin olmasını, bașarılı bir alışveriş olarak değerlendirilmektedir. Hedonik değer, tüketicinin rutinin dışında değişik zevk ve heyecanlar yaşamayı planlaması ya da en 
azından sıradanlıktan kaçması ile tanımlamaktadır. Bu kapsamda, faydacı değer ile hedonik değer kıyaslandığında, hedonik değer eğlence odaklı, faydacı yaklaşıma oranla çok daha öznel ve en nihayetinde zevke dayalı bir süreç olarak gerçekleşmektedir (Carpenter vd., 2005: 45).“Hedonik alışveriş değeri", alışveriş deneyiminin çok duyusal, arzu ile ilgili ve duygusal yönlerinden alınan değeri yansıtırken, "faydacı alışveriş değeri", ürünlerin ve/veya bilgilerin verimli bir şekilde edinilmesini yansıtır ve daha görev odaklı, bilișsel ve alışverişin duygusal olmayan sonucu ortaya koyar (Holbrook ve Hirschman, 1982). Hedonik alışveriş değeri, faydacı alışveriş değerine kıyasla çok daha kişisel olsa da, bir görevi tamamlamanın beraberinde eğlenceye ya da neșeye yönelik bir alışveriş deneyimini de elde edilebilmektedir. Bu sebeple, hedonik alışveriş değeri, duygusal anlamı ve bunun yanında potansiyel bir hazzı da yansıtmaktadır (Jones vd., 2006: 975). Bu anlamda, hedonik alışveriş değerine nazaran çok daha bilişsel, pek duygusal olmayan, hatta bir anlamda görev odaklı olan bir süreç olarak da nitelendirilebilmektedir (Jones vd., 2006: 974).

Tüketici değeri, literatürde yaygın olarak iki alt bileşenle ifade edilmektedir. Bunlar faydacı ve hedonik değerlerdir (Babin vd., 1994). Tüketici alışveriş değeri, tüketici davranış niyetlerini etkilemektedir (Lee vd. 2009). Faydacı ve hedonik alışveriş değerleri yalnızca tüketici memnuniyeti algısını etkilemekle kalmaz, aynı zamanda davranışsal niyetleri de doğrudan etkiler (Chen ve Chen, 2010; Bakırtaş vd., 2015). Küresel tüketici kültürüyle özdeşleşmede ise küresel tüketici kültürüne duyulan ilginin ötesine geçilmekte ve küresel tüketici kültürüyle özdeşleşen tüketiciler küresel markaları tercih etmekte ve bunu bir yaşam tarzı olarak benimsemektedirler (Cleveland vd., 2015). Tüketiciler, satın almaya karar verirken hem faydacı hem de hedonik alışveriş değerinden etkilenir. Bazı ürünleri hedonik arzularını tatmin etmek için, bazıları da faydacı beklentilerini karşılamak için tercih ederler (Bakırtaş vd., 2015). Lysonski ve Durvasula(2013) materyalizmin, küresel tüketici kültürüyle özdeşleşmeyi pozitif yönde etkilediğini, tüketici etnosentrizminin ise küresel tüketici kültürüyle özdeşleşmeye etkisi olmadığını göstermişlerdir. Öte yandan materyalizmin hedonik ve faydacı alışveriş değeri ile iliş̧kisini inceleyen ve anlamlı ilişkiler bulan çalışmalar (Seo ve Huh, 2004) ve ayrıca materyalizm ile hedonik tüketim arasında pozitif yönlü ilişkiler bulan çalışmalar (Niyet ve Taşpınar, 2020) bulunmaktadır. Ayrıca hedonik çerçevede pek çok tüketici, modernlik ile özdeşleştirdikleri çeşitli ünlü ya da markalı ürünleri, temel ihtiyaçlarının sınırlarını aşan beklentilerini tatmin edebilmek ve daha da önemlisi kendilerinin de bu modern dünyanın bir parçası olduklarını diğer bireylere de ispat etmek için talep etmektedirler (Batra vd., 2000; Şengün ve Karahan, 2013). Ayrica Wahyuningsih ve Fatmawati (2016) küresel marka tercihleri ile hedonik yaşam tarzı arasında pozitif bir iliş̧i olduğunu göstermiştir. Dolayısıyla küresel tüketici kültürüyle özdeşleşen bireylerin hedonik alışveriş değerlerinin yüksek çıkması beklenen bir sonuç olacaktır. Öte yandan küresel ürünleri tüketmenin nedenleri arasında; kozmopolit olma, ileri teknolojili olma, yüksek statü sağlama (Özsomer, 2012; Batra vd. 2000), daha kaliteli ve prestijli bulma (Lee vd., 2008; Steenkamp vd., 2003; Izberk-Bilgin, 2008), küresel tüketimi ilerlemeyle ilişki bulma, modern bulma, kolay ulaşllabilir ve verimli bulma (Steenkamp ve De Jong, 2010) statü sağlama (Zhou vd., 2008) ve yerel ürünlere nazaran daha kaliteli bulma (Holt vd., 2004) sıralanmıştır. Dolayısıyla bu açıklamalar bir bütün olarak düşünüldüğünde küresel tüketici kültürüyle özdeşleşen bireylerin hem hedonik hem de faydacı alışveriş değerlerine pozitif yönde önem verdikleri değerlendirilebilir. $\mathrm{Bu}$ kapsamdaaraştırmanın amacı doğrultusunda aşağıdaki hipotezler geliştirilmiştir:

$\mathrm{H}_{1}$. Küresel Tüketici Kültürüyle Özdeşleşmenin Hedonik Alışveriş Değeriüzerinde pozitif etkisi vardır.

H2. Küresel Tüketici Kültürüyle Özdeşleşmenin Faydacı Alışveriş Değeri üzerinde pozitif etkisi vardır.

Aşağıda Görsel 1'de araştırma modeli sunulmuştur. 


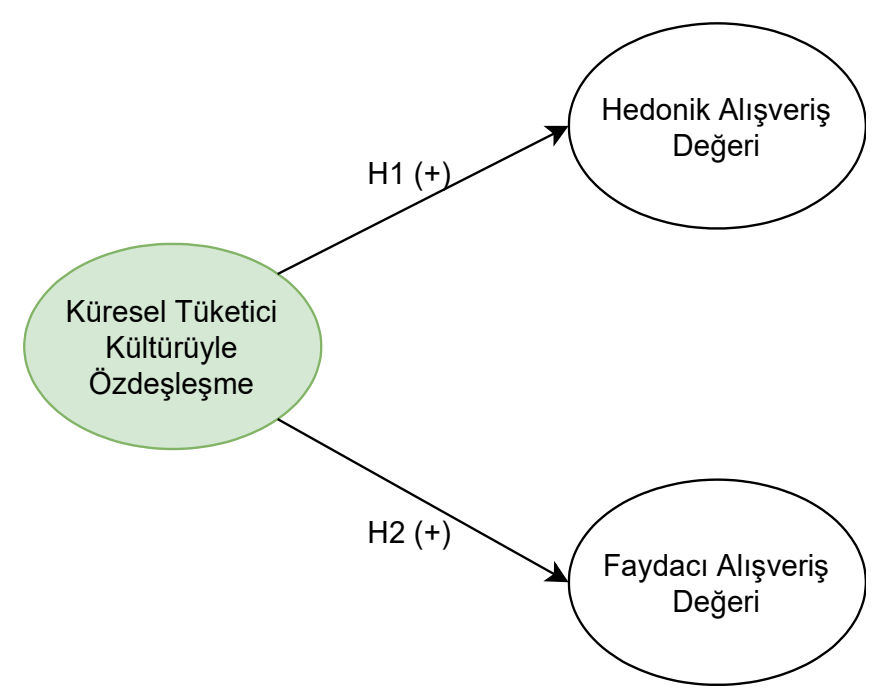

Görsel 1. Araştırma modeli

\section{Araştırma Metodolojisi}

\section{Ölçekler}

Anket kapsamında, araştırmacı tarafından "Kişisel Bilgi Formu" yanı sıra, "Küresel Tüketici Kültürüyle Özdeşleşme Ölçeği", "Hedonik Alışveriş Değeri Ölçeği" ve "Faydacı Alışveriş Değeri Ölçeği" oluşturulmuştur. Hedonik alışveriş değeri ve faydacı alışveriş değerine iliş̧in verilerin elde edilebilmesi için Babin vd. (1994) tarafından hedonik alışveriş değerinin tespiti için geliştirilen 13 maddeden oluşan ölçek yanında faydacı alışveriş değerinin tespiti için geliştirdikleri 7 maddeden olușan ölçek kullanılmıștır. Ayrıca "Küresel Tüketici Kültürüyle Özdeșleșme" düzeyine ilișkin veriler için Cleveland ve Laroche'den (2007) uyarlanan sekiz maddeden oluşan ölçek kullanılmıştır. Sorular için yedili likert ölçeği kullanılmıştır. Bir uçta "kesinlikle katılıyorum" ifadesi bulunmakta ve "7" puan ile gösterilmekte, diğer uçta ise "kesinlikle katılmıyorum" ifadesi bulunmakta ve "1" puan ile değerlendirilmektedir. Bu kapsamda, maddelere verilen yanıtların ortalamaları, katılımcıların konuya ilişkin düzeylerini ortaya koymaktadır. Aşağıda Görsel 2'de kullanılan ölçekler ve maddeleri verilmiştir

\begin{tabular}{|l|c|l|}
\hline Değişken & No & Maddeler \\
\hline & 1 & $\begin{array}{l}\text { Hangi ürünleri tüketeceğime dair tercihim, yabancı veya küresel şirketlerin } \\
\text { reklamlarından etkilenmektedir. }\end{array}$ \\
\cline { 2 - 3 } & 2 & $\begin{array}{l}\text { Yabancı veya küresel markaların reklamları, satın alacağım ürünlerle ilgili } \\
\text { marka seçimlerim üzerinde güçlü bir etki meydana getirmektedirler. }\end{array}$ \\
\cline { 2 - 3 } $\begin{array}{l}\text { Küresel } \\
\text { Tüketici } \\
\text { Kültürüyle } \\
\text { Özdeşleşme }\end{array}$ & 3 & $\begin{array}{l}\text { Benim yaş grubumda olup yurtdışında yaşayan kişilerin tüketim eğilimlerini } \\
\text { göz önünde bulunurum. }\end{array}$ \\
\cline { 2 - 3 } & 4 & $\begin{array}{l}\text { Giyim tarzı, yaşam alanı düzeni ya da boş zamanımı değerlendirmek için } \\
\text { tercih ettiğim ürün ve hizmetler de dahil olmak üzere, yaşam tarzımı global } \\
\text { bir tüketici olacak biçimde şekillendirmekteyim. }\end{array}$ \\
\cline { 2 - 3 } & 5 & $\begin{array}{l}\text { Dünya genelindeki yaşam tarzl, moda ve genel tüketim eğilimleri ile ilgili } \\
\text { dergiler okumayı seviyorum. }\end{array}$ \\
\cline { 2 - 3 } & 6 & $\begin{array}{l}\text { Dünyanın birçok ülkesinde popüler olduğunu düşündüğüm ürünleri } \\
\text { tüketmeyi tercih ediyorum }\end{array}$ \\
\cline { 2 - 3 } & 7 & "Yerel" sınırları aşmış olan ürünleri tercih ederim. \\
\hline
\end{tabular}




\begin{tabular}{|c|c|c|}
\hline \multirow{13}{*}{$\begin{array}{l}\text { Hedonik } \\
\text { Alışveriş } \\
\text { Değeri }\end{array}$} & 1 & Alıșveriș gerçekten bir eğlencedir. \\
\hline & 2 & $\begin{array}{l}\text { Yapmış olabileceğim diğer şeylerle kıyaslandığında, alışverişte geçirdiğim } \\
\text { zaman gerçekten keyiflidir. }\end{array}$ \\
\hline & 3 & Alıșveris boyunca aramanın heyecanını hissederim. \\
\hline & 4 & Alışveriș gerçekten bir kaçıș hissi verir. \\
\hline & 5 & Heyecan verici yeni ürünlere yoğunlașmaktan keyif alırım. \\
\hline & 6 & $\begin{array}{l}\text { Sadece satın almış olabileceğim ürünlerden değil, alışverişin kendisinden de } \\
\text { keyif alırım. }\end{array}$ \\
\hline & 7 & Zorunda olduğum için değil, istediğim için alıșverișe devam ederim. \\
\hline & 8 & Alışveriște anlık kararlarla hareket edebildiğim için iyi vakit geçiririm. \\
\hline & 9 & Alıșveriș sırasında problemlerimi unuturum. \\
\hline & 10 & Alıșveriș sırasında bir macera hissine kapılırım. \\
\hline & 11 & Alșveriș iyi bir zaman tüketme biçimi değildir. \\
\hline & 12 & Alışveriş sırasında kendimi gerçekten şansız hissederim. \\
\hline & 13 & Alıșveriș boyunca pek çok șeyi hayal edebilirim. \\
\hline \multirow{7}{*}{$\begin{array}{l}\text { Faydacı } \\
\text { Alş̧veriş } \\
\text { Değeri }\end{array}$} & 1 & Alıșverișlerimi genellikle istediğim șekilde tamamlarım. \\
\hline & 2 & Alıșverișlerimde genellikle gerçekten ihtiyacım olan șeyi alamam. \\
\hline & 3 & Genellikle alıșveriș sırasında, tam da aradığım șey(ler)i bulurum. \\
\hline & 4 & $\begin{array}{l}\text { Alışverişimi tamamlamak için başka mağaza(lar)a gitmek zorunda kalınca } \\
\text { hayal kırıklığına uğrarım. }\end{array}$ \\
\hline & 5 & Alışverișlerimde genellikle başarılı bir sonuca ulașırım. \\
\hline & 6 & Alıșverișlerimde genellikle kendimi akıllı buluyorum. \\
\hline & 7 & $\begin{array}{lcccccc}\begin{array}{l}\text { Alışveriş çok hızlı sona erdiği } \\
\text { gerçekleştirdiğimi düşünürüm. }\end{array} & \text { zaman } & \text { iyi } & \text { bir } & \text { mağaza } & \text { ziyaret } \\
\end{array}$ \\
\hline
\end{tabular}

Görsel 2. Araştırma kapsamında kullanılan ölçekler

\section{Örnekleme ve Veri Toplama}

Araştırmanın evrenini Türkiye'de yaşayan ve küresel markalı ürünleri tüketen tüketiciler meydana getirmektedirler. Ankette katılımcılara "Küresel Markaları Tüketiyor musunuz?" sorusu sorulmuş, bu soruya evet cevabı veren katılımcların anketi değerlendirilmiştir. Araştırmanın örneklemi kolayda örnekleme yöntemi ile belirlenmiștir. Anket formları, katılımcılara online platformlar üzerinden ulaştırılmıştır. Katılımcıların doldurdukları anketler arasından hatalı ya da geçersiz olanlar çıkarılmış ve geriye kalan 302 adet anket formu çalışma kapsamında incelenmiştir. Genel itibariyle sosyal bilimlerde tarama türü araştırmalarda 200-300 arası örneklem sayıları yeterli görülmektedir (Gürbüz ve Şahin, 2014: 128).

\section{Veri Analizi ve Sonuçları}

Nicel araştırma yöntemiyle gerçekleştirilmiş olan bu çalışmada katılımcıların, küresel tüketici kültürüyle özdeşleşme düzeyleri ölçülerek, bunun faydacı ve hedonik alışveriş değerleri ile ilgili yargılar üzerindeki etkisi ortaya konulmaya çalışılmıştır.

Modeldeki yapıların geçerliliği ve yapılar arasındaki ilişsileri analiz etmek için Kısmi En Küçük Kareler (PLS - Partial Least Squares) yapısal eşitlikmodellemesi kullanılmıştır. Son derece karmaşık tahmini modelleri ve çokmaddeli yapıları, hem doğrudan hem de dolaylı yollar ile analiz etmek PLS ilemümkündür. PLS küçük örneklem boyutlarının üstesinden gelebilir ve verilerdekiçok değişkenli homojenlik ve normallik gereksinimlerini de zorunlu kılmaz (Hair vd., 2014). PLS temel bileşenler analizi ve regresyonun tekrarlamalı bir kombinasyona dayanmakta, modeldeki yapıların değişimini açıklamayı amaçlamaktadır (Chin, 1998). Araştırmada ilk olarak ölçeğin güvenilirlik ve geçerlilik testleri bağlamında; madde güvenilirliği için faktör yükleri, iç tutarlılık güvenilirliği için Cronbach's 
Alpha ve birleşik güvenilirlik değerleri, birleşme geçerliliği için açıklanan ortalama varyans değerleri ve son olarak ayrışma geçerliliği için çapraz yükler, Fornell-Larcker Kriteri ve HTMT Kriteri değerlerine bakılmıştır. Akabinde Kısmi En Küçük Kareler yöntemi ile yapısal eşitlik modelinin tahmini gerçekleștirilmiştir.

\section{Tanımlayıcı Ístatistikler}

Aşağıda Görsel 3'te görüleceği üzere katılımcların 68'ini kadın 234'ünü erkek bireyler oluşturmaktadır. Katılımcılardan 51 kişi evli, 251 kişi ise bekârken, 18-24 yaş arasında 102 kişi, 2534 yaş arasında 155 kişi ve 35-44 yaş arasında 45 kişi bulunmaktadır. Bunlara ilave olarak katılımcllardan 18 kişi ilköğretim, 43 kişi lise, 63 kişi önlisans, 138 kişi lisans, 39 kişi yüksek lisans eğitim düzeyindeyken, 0-3000 TL gelir seviyesinde 142 kişi, 3001-4500 TL gelir seviyesinde 117 kişi, 4501-6000 TL gelir seviyesinde 41 kişi ve son olarak 2 kişi 6001-7500 TL gelir seviyesindedir.

\begin{tabular}{ccccc}
\hline & & Frekans & Yüzde & Kümülatif Yüzde \\
\hline \multirow{3}{*}{ Cinsiyet } & Kadın & 68 & 22,5 & 22,5 \\
& Erkek & 234 & 77,5 & 100 \\
& Toplam & 302 & 100 & \\
\hline \multirow{3}{*}{ Medeni Durum } & Evli & 51 & 16,9 & 16,9 \\
& Bekar & 251 & 83,1 & 100 \\
& Toplam & 302 & 100 & 33,8 \\
& $18-24$ & 102 & 33,8 & 85,1 \\
Yaş & $25-34$ & 155 & 51,3 & 100 \\
& $35-44$ & 45 & 14,9 & 6 \\
& Toplam & 302 & 100 & 20,2 \\
& İlköğretim & 18 & 6 & 81,1 \\
& Lise & 43 & 14,2 & 99,7 \\
& Önlisans & 63 & 20,9 & 100 \\
& Lisans & 138 & 45,7 & 47 \\
& Yüksek Lisans & 39 & 12,9 & 85,8 \\
& Doktora & 1 & 0,3 & 99,3 \\
& Toplam & 302 & 100 & 100 \\
\hline \multirow{5}{*}{ Gelir } & $0-3000 T L$ & 142 & 47 & \\
& 3001-4500TL & 117 & 38,7 & \\
& 4501-6000TL & 41 & 13,6 & \\
& 6001-7500TL & 2 & 0,7 & \\
& Toplam & 302 & 100 & \\
\hline
\end{tabular}

Görsel 3.Katılımcı demografik veriler

Aşağıda ilk olarakaraştırma modeli ölçeğin güvenilirlik ve geçerlilik sonuçları irdelenmiş ve akabinde hipotez testleri değerlendirilmiştir.

\section{PLS Ölçüm Model Sonuçları}

Araştırmada kullanılan ölçekler için geçerlik ve güvenilirlik çalışmaları gerçekleştirilmiştir. Bu kapsamda, madde güvenilirliği, iç tutarlılık güvenilirliği, birleşme geçerliği ve ayrışma geçerliği incelenmiştir.

Madde güvenilirliğini test etmek için her madde için standardize madde yüklerine bakılmıştır. Faktör yüklerinin 0.5 değerinden yüksek olması madde güvenilirliği için kabul edilir bir sonuç olarak değerlendirilmektedir (Hair vd., 2010).

İç tutarlılık güvenilirliği (Internal Consistency Reliability) için Cronbach Alpha katsayısı ve birleşik güvenilirlik katsayısı (Composite Reliability-CR) katsayısı dikkate alınmaktadır. Her iki katsayıdan 
da benzer şekilde 0.70 ile 0.90 arasında değer alması beklenir. 0.95'in üzerinde Cronbach Alpha değeri ise değişkenlerin ölçtükleri durumlar arasında fazla benzerlik olduğuna işarettir (Hair vd., 2017).

Birleşme geçerliliği (Convergent validity) için ifadelerin açıklanan ortalama varyans değerlerine (Average Variance Extracted - AVE) dikkat edilmiştir. AVE değerinin sınır değer olan 0.50 ve üzeri olarak görülmesi gerekmektedir (Fornell ve Larcker, 1981).

Ayrışma geçerliliğinin (Discriminant validity) tespit edilmesi için kullanılabilecek üç kriter bulunmaktadır. Bunlardan ilki çapraz yükleme (cross-loading) değeridir. Bu kritere göre bir ifadenin altında yer aldığı değişkene ait faktör yükü diğer değişkenlerde aldığı faktör yükünden daha yüksek olmalıdır. Kriterlerden bir diğeri Fornell-Larcker kriteridir. Fornell-Larcker tablosunda AVE değerlerinin karekökleri olan değerler diğer değișkenlerin değerleri ile karşılaștırılır ve köşegen değerlerin en büyük olması beklenir. Başka bir alternatif olan HTMT kriteri, değişkenlerin ifadelerinin korelasyonlarının geometrik ortalamalarını ifade etmektedir. HTMT değerlerinin 0,9 altında olması beklenir (Hair vd., 2017; Henseler vd., 2015).

\begin{tabular}{|c|c|c|c|c|c|}
\hline & \multicolumn{2}{|c|}{ Madde Güvenilirliği } & \multicolumn{2}{|c|}{ İç Tutarlılık Güvenilirliği } & \multirow{2}{*}{$\begin{array}{c}\text { Birleşme } \\
\text { Geçerliliği } \\
\text { Açlklanan } \\
\text { Ortalama } \\
\text { Varyans (Average } \\
\text { Variance Extracted } \\
\text { AVE) }>0.5\end{array}$} \\
\hline Değişkenler & Maddeler & $\begin{array}{c}\text { Faktör Yükleri } \\
>0.5\end{array}$ & $\begin{array}{l}\text { Cronbach's } \\
\text { Alpha }>0.7\end{array}$ & $\begin{array}{c}\text { Birleşik } \\
\text { Güvenilirlik(Composite } \\
\text { Reliability-CR) } \\
>0.5\end{array}$ & \\
\hline \multirow{8}{*}{$\begin{array}{l}\text { Küresel } \\
\text { tüketici } \\
\text { Kültürüyle } \\
\text { Özdeşleşme } \\
\text { (KTKÖ) }\end{array}$} & KTKÖ1 & 0.854 & \multirow{8}{*}{0.929} & \multirow{8}{*}{0.942} & \multirow{8}{*}{0.669} \\
\hline & KTKÖ2 & 0.815 & & & \\
\hline & KTKÖ3 & 0.863 & & & \\
\hline & KTKÖ4 & 0.801 & & & \\
\hline & KTKÖ5 & 0.712 & & & \\
\hline & KTKÖ6 & 0.772 & & & \\
\hline & KTKÖ7 & 0.883 & & & \\
\hline & KTKÖ8 & 0.832 & & & \\
\hline \multirow{9}{*}{$\begin{array}{c}\text { Hedonik } \\
\text { Alışveriş̧ } \\
\text { Değeri (HED) }\end{array}$} & HED1 & 0.749 & \multirow{9}{*}{0.911} & \multirow{9}{*}{0.928} & \multirow{9}{*}{0.590} \\
\hline & HED2 & 0.753 & & & \\
\hline & HED3 & 0.660 & & & \\
\hline & HED5 & 0.842 & & & \\
\hline & HED6 & 0.802 & & & \\
\hline & HED7 & 0.902 & & & \\
\hline & HED8 & 0.806 & & & \\
\hline & HED12 & 0.608 & & & \\
\hline & HED13 & 0.751 & & & \\
\hline \multirow{5}{*}{$\begin{array}{l}\text { Faydacı } \\
\text { Alışveriş } \\
\text { Değeri } \\
\text { (FAYD) }\end{array}$} & FAYD1 & 0.648 & \multirow{5}{*}{0.773} & \multirow{5}{*}{0.845} & \multirow{5}{*}{0.522} \\
\hline & FAYD2 & 0.701 & & & \\
\hline & FAYD3 & 0.694 & & & \\
\hline & FAYD6 & 0.751 & & & \\
\hline & FAYD7 & 0.809 & & & \\
\hline
\end{tabular}

Görsel 4. Madde Güvenilirliği, İç Tutarlılık Güvenilirliği ve Birleşme Geçerliliği Sonuçları

Faktör yükleri 0,5 değerinin altında olan maddeler analizden çıkarılmıştır. 


\begin{tabular}{cccc}
\hline \multicolumn{4}{c}{ Çapraz Yükler } \\
\hline & FAYD & HED & KTKÖ \\
\hline FAYD1 & 0.648 & 0.396 & 0.395 \\
FAYD2 & 0.701 & 0.374 & 0.382 \\
FAYD3 & 0.694 & 0.432 & 0.407 \\
FAYD6 & 0.751 & 0.472 & 0.491 \\
FAYD7 & 0.809 & 0.576 & 0.624 \\
\hline HED1 & 0.452 & 0.749 & 0.731 \\
HED12 & 0.503 & 0.608 & 0.532 \\
HED13 & 0.519 & 0.751 & 0.672 \\
HED2 & 0.467 & 0.753 & 0.646 \\
HED3 & 0.522 & 0.660 & 0.604 \\
HED5 & 0.525 & 0.842 & 0.669 \\
HED6 & 0.462 & 0.802 & 0.625 \\
HED7 & 0.546 & 0.902 & 0.755 \\
HED8 & 0.404 & 0.806 & 0.659 \\
\hline KTKÖ1 & 0.497 & 0.721 & 0.854 \\
KTKÖ2 & 0.566 & 0.682 & 0.815 \\
KTKÖ3 & 0.425 & 0.744 & 0.863 \\
KTKÖ4 & 0.621 & 0.654 & 0.801 \\
KTKÖ5 & 0.622 & 0.612 & 0.712 \\
KTKÖ6 & 0.497 & 0.648 & 0.772 \\
KTKÖ7 & 0.485 & 0.766 & 0.883 \\
KTKÖ8 & 0.555 & 0.775 & 0.832 \\
\hline Fornell-Larcker Kriteri Değerleri (AVE'nin karekökü) \\
\hline FAYD & 0.723 & \\
HED & 0.635 & 0.768 & \\
KTKÖ & 0.654 & 0.858 & 0.818 \\
\hline \multicolumn{4}{c}{} \\
\hline FAYD & HTMT Kriteri Değerleri>0.9 \\
HED & 0.747 & & \\
KTKÖ & 0.749 & 0.831 & \\
\hline & & \\
\hline
\end{tabular}

Görsel 5. Ayrışma Geçerliliği Sonuçları

Yukarıda Görsel 4'de görüleceği üzere bütün faktör yükleri 0.5 değerinden yüksek olduğu için madde güvenilirliği, değişkenler için Cronbach's Alpha değerleri 0.7 değerinden ve Birleşik Güvenilirlik değerleri 0.5 değerinden yüksek olduğundan iç tutarlılık güvenilirliği, Açıklanan Ortalama Varyans değerleri 0.5 değerinden yüksek olduğundan birleşme geçerliliği sağlanmıștır. Ayrıca Görsel 5'de görüleceği üzere ayrışma geçerliliği testlerinden çapraz yükleme sonuçlarına göre bir ifadenin altında yer aldığı değişkene ait faktör yükü diğer değişkenlerde aldığı faktör yükünden daha yüksek olduğu için; Fornell-Larcker kriterine göre köșegen değerlerin en büyük olması sebebiyle ve son olarak HTMT değerleri 0,9 altında olduğu için ayrışma geçerliliği sağlanmıştır.

\section{PLS Yapısal Model Sonuçları}

Așağıda Görsel 6 ve Görsel 3'de özetlendiği üzere iki hipotezde desteklenmiştir.

\begin{tabular}{lccccc}
\hline Hipotezler & Yol & $\beta$ & S.S. & $\begin{array}{c}\text { T } \\
\text { değeri }\end{array}$ & $\begin{array}{c}\text { değer } \\
\mathrm{i}\end{array}$ \\
\hline
\end{tabular}




\begin{tabular}{|c|c|c|c|c|c|c|}
\hline $\begin{array}{l}\text { Özdeşleşmenin Hedonik Alışveriş } \\
\text { Değeri üzerinde pozitif etkisi } \\
\text { vardır. }\end{array}$ & KTKÖ -> HED & 0.858 & 0.020 & 42.104 & 0.000 & $\begin{array}{c}\text { Desteklend } \\
\text { i }\end{array}$ \\
\hline $\begin{array}{l}\mathrm{H}_{2 .} \text { Küresel Tüketici Kültürüyle } \\
\text { Özdeşleşmenin Faydacı Alışveriş } \\
\text { Değeri üzerinde pozitif etkisi } \\
\text { vardır. }\end{array}$ & KTKÖ -> FAYD & 0.654 & 0.034 & 19.446 & 0.000 & $\begin{array}{c}\text { Desteklend } \\
\text { i }\end{array}$ \\
\hline
\end{tabular}

Gösel 6. Hipotez Test Sonuçları

Küresel tüketici kültürüyle özdeşleşme, hedonik alışveriş değerini pozitif yönde ve güçlü bir şekilde ( $\beta=0.858, t=42.104, p<0.001)$ etkilemektedir. Bu nedenle $\mathrm{H} 1$ hipotezi kabul edilmiştir. Ayrıca Küresel tüketici kültürüyle özdeşleşme, faydacı alışveriş değerini pozitif yönde $(\beta=0.654, t=19.446$, $\mathrm{p}<0.001$ ) etkilemektedir. Bu nedenle $\mathrm{H} 2$ hipotezi desteklenmiştir. Hedonik alışveriş değerindeki varyansın \%73,7'si, faydacı alışveriş değerindeki varyansın \%42,8'i açıklamıștır. Küresel tüketici kültürüyle özdeşleşme, faydacı alışveriş değerine göre hedonik alışveriş değeri üzerinde daha yüksek seviyede etkilidir.

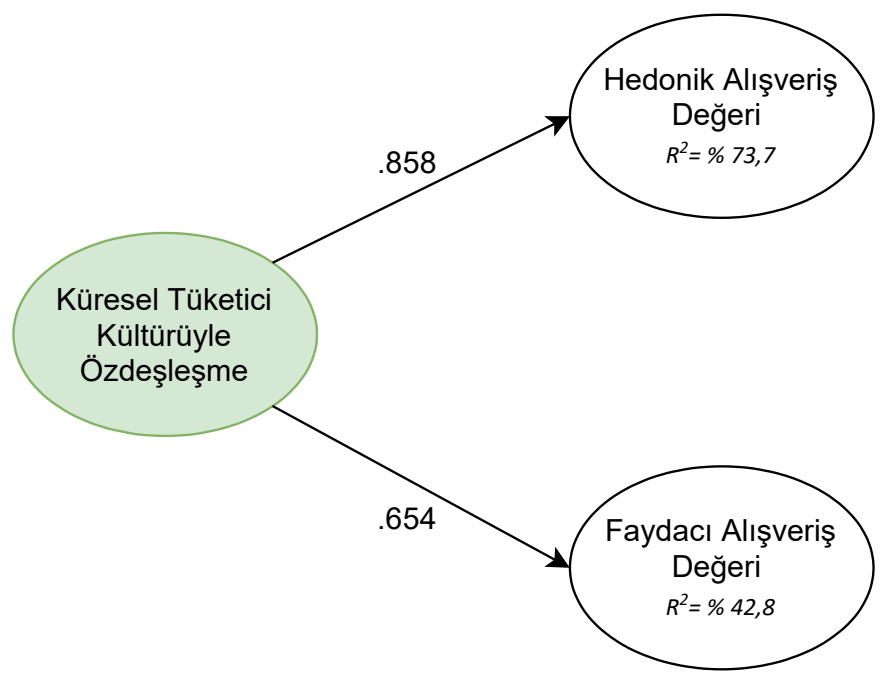

$p<0.001$

Görsel 7. Yapısal Modelin PLS Sonuçları

\section{Tartışma ve Sonuç}

Bu çalışmada küresel tüketici kültürüyle özdeşleşmenin, faydacı ve hedonik alışveriş değerleri üzerindeki etkisi ortaya konulmaya çalışılmıştır. Küresel tüketici kültürüyle özdeşleşmenin; hedonik alışveriş değerini pozitif yönde ve güçlü bir şekilde, faydacı alışveriş değerini pozitif yönde etkilediği tespit edilmiştir. Çalışmanın hem teorik hemde pratik uygulamalar için çıkarımlar bağlamında önemli tespitleri bulunmaktadır.

Küresel ürünleri tüketmenin nedenleri arasında, modern, kolay ulaşllabilir ve tüketici odaklı bulma (Steenkamp ve De Jong, 2010), yerel ürünlere göre daha kaliteli ve dayanıklı bulma (Holt vd., 2004) sıralanmıștır. Ayrıca küresel markaların daha kaliteli ve prestijli olarak değerlendirildiğini ortaya koyan çalışmalar da (Lee vd., 2008; Steenkamp vd., 2003; Izberk-Bilgin, 2008) bulunmaktadır. Yukarıda bahsi geçen çalışmaların küresel ürünlere olan talep nedenleri arasında kalite, verim vb. 
faydacı yönler de yeralmaktadır. Faydacı alışveriş değeri, alışveriş deneyiminin bilişsel, görev ve fayda odaklı rasyonel yönlerinin yansıtmaktadır. Dolayısıyla, bu çalışmanın küresel tüketici kültürüyle özdeşleşmenin faydacı alışveriş değerini pozitif etkilediği bulgusuyla, bahsi geçen çalışmaların bulgularının benzediği ifade edilebilir. Ayrıca Wahyuningsih ve Fatmawati (2016) küresel marka tercihleri ile hedonik yaşam tarzıarasında pozitif bir ilişki olduğunu göstermiştir. Dolayısıyla sözkonusu çalışmanın bulguları, bu çalışmanın küresel tüketici kültürüyle özdeşleşmenin hedonik alışveriş değerinipozitif yönde etkilemesi bulgusuyla dolaylı yoldan benzemektedir. Bu çalışmanın sonuçları ile küresel tüketici kültürüyle özdeșleșmenin, hedonik ve faydacı alıșveriş değerleri üzerinde ne ölçüde ve ne yönde etki ettiği hakkında alanyazında yer alan boşlukların doldurulmasında orjinal katkı sağlandığı düşünülmektedir.

Ayrıca küresel tüketici kültürünü benimseme düzeyi yüsek bireylerin materyalizme verdikleri önemin yüksek olması (Cleveland vd., 2015), materyalizm ile hedonik tüketim arasında pozitif yönlü ilişkiler olması (Niyet ve Taşpınar, 2020), yine aynı şekilde hedonik çerçevede pek çok tüketici, modernlik ile özdeşleştirdikleri çeşitli ünlü ya da markalı ürünleri, temel ihtiyaçlarının sınırlarını aşan beklentilerini tatmin edebilmek ve daha da önemlisi kendilerinin de bu modern dünyanın bir parçası olduklarını diğer bireylere de ispat etmek için talep ettikleri (Batra vd., 2000; Şengün ve Karahan, 2013) düşünüldüğünde ve ünlü markalarında genelikle küresel markalar olduğu gözöününe alıdığında, faydacı bağlamda ise küresel markaları daha kaliteli olarak algılandığı (Holt vd., 2004; Lee vd., 2008; Steenkamp vd., 2003; Izberk-Bilgin, 2008) göz önüne alındığında; küresel tüketici kültürüyle özdeşleșen bireylerin hedonik ve faydacı alışveriş değelerinin yüksek çıkması beklenen sonuçlardır.

Araştırmanın en dikkat çekici sonucu küresel tüketici kültürüyle özdeşleşmenin hedonik alışveriş değerini pozitif yönde ve güçlü bir şekilde etkiliyor olmasıdır. Bu bulgudan hareketle küresel işletmeler için önemli çıkarımlar yapılabilir. Küresel işletmelerin pazarlama planlarını özellikle tüketicilerin hedonik alışveriş değerini gözönüne alarak yapmalarında fayda olduğu düşünülebilir. Örneğin ürün tasarımlarının, alışveriş mağaza atmosferlerinin dizaynlarının, tutundurma faaliyetlerinde reklam stratejilerinin bu doğrultuda planlanması, yine aynı şekilde e-ticaret site tasarımlarının hedonik alışveriş değerine hitap edecek şekilde modern tasarımı vb. uygulamalar icra edilebilir. Araştırma kapsamındaki diğer bulgu olan küresel tüketici kültürüyle özdeşleşmenin faydacı alışveriş değerinipozitif yönde etkilemesi gözönüne alınarak da yine aynı şekilde küresel işletmelere pratik uygulamalar için çıkarımlar yapılabilir. Hedonik alışveriş değeri kadar olmasa da faydacı alışveriş değerine de küresel işletmelerin dikkate almasında ve ürünün kolay bulunabilirliği, kalitesi ve fiyatı gibi faydacı unsurları da gözönüne alarak üretim proseslerinin, satış stratejilerinin, perakende satış sistemlerinin uygun kalite, uygun maliyet ve kolay bulunabilme sağlayacak şekilde planlamalarında fayda olacağı düşünülmektedir. Zira küresel tüketici kültürüyle özdeşleșmiş bireyler özellikle hedonik alışveriş değeri bașta olmak üzere, hem hedonik hem de faydacı alış veriş değerlerine pozitif yönde önem vermektedirler.

Küreselleşme ve tüketicilerin buna yönelik karmaş̧ı tepkileriyle, şirketlerin pazarlama stratejilerini yeniden değerlendirirken sınırların ötesinde verimli bir pazarlama stratejisibelirlemelerinde fayda bulunmaktadır. Cleveland (2018)'e göre piyasaların küreselleşmesi, çokuluslu şirketleri yerelleștirilmiş olanlar yerine küresel marka portföyleri sunmaya teșvik etmektedir. Her yönüyle hızla değișen dünyada, tüketicilerin kültürel eğilimlerinin oynadığı rolü belirlemek, küresel ve yerel tüketimin gelişen doğasına uyum sağlamak önemlidir. Küresel tüketici kültürüyle özdeşleşme düzeyleri yüksek olan bireyler için özellikle ürün tasarımı ve reklam aktivitelerinde geleneksel bir uluslararası pazarlama strateji olan adaptasyon stratejilerinin zararlı olacağı düşünülebilir. Bu kapsamda bu bireylerin yoğun olduğu toplumlar için özellikle ürün tasarımı, reklam ve mağaza atmosferi vb. işlevlerinde standardizasyon stratejisinin uygulanmasında fayda bulunmaktadır. Zira adaptasyon stratejisiyle yerel kültüre göre uyarlama yapılması, küresel tüketici kültürünü ortak bir dünya kültürü gören ve bu gruba dair aidiyet hissini yaşamak isteyen müșteriler için iyi bir strateji 
olmayacaktır. En azından küresel marka kimliği ve küresel tüketim kültürü kavramlarına zarar vermeden adaptasyon stratejilerinin uygulanması değerlendirilebilir.

Küresel tüketici kültürüyle özdeşleşme kavramı uluslararası pazarlama literatürü için yeni kavram olması hasebiyle hem öncüllerinin(antecedents) hem de etkilediği sonuç değişkenlerinin (outcomes) araştırılmaya devam edilmesinin önemli olduğu düşünülmektedir. Araştırmanın sadece Türkiye kapsamında yapılmış olması hasebiyle farklı kültürlerde de tekrarlanmasında fayda bulunmaktadır. Gelecekteki çalışmaların ülkemiz dışında diğer ülkelerde de araştırma modelinin test edilmesi modelin geçerliliğini ve farklı ülkelere genelleştirilebilirliğini arttıracaktır. Ayrıca ürün kategorileri bazında da farklı çalışmaların yapılmasının önemli olduğu düşünülmektedir.

\section{Kaynakça}

Akaka, M. A.ve Alden, D. L. (2010). Global Brand Positioning and Perceptions: International Advertising and Global Consumer Culture. InternationalJournal of Advertising, 29(1), 37-56.

Alden, D.L., Steenkamp, J.-B.E. ve Batra, R. (1999).Brand Positioning Through Advertising in Asia, North America, and Europe: The Role of Global Consumer Culture", Journal of Marketing, 63(1), 75-87.

Appadurai, A. (1990). Disjuncture and Difference in the Global Economy. Theory Culture \& Society 7 (2/3), 295-310.

Aydın, S. (2010). Hedonik Alışverişin Cinsiyet, Gelir ve Yerleşim. Süleyman Demirel Üniversitesi İktisadi ve İdari Bilimler Fakültesi Dergisi, 15(3), 435-452.

Bakırtaş, H., Bakırtaş, İ. ve Çetin, M. A. (2015). Effects of Utilitarian and Hedonic Shopping Value and Consumer Satisfaction on Consumer Behavioral Intentions. Ege Akademik Bakış Dergisi, 15(1), 91-98.

Babin, B.J., Darden, W.R. ve Griffin, M. (1994). Work and/or Fun: Measuring Hedonic and Utilitarian Shopping Value. Journal of Consumer Research, 20, 644-656.

Batra, R., Ramaswamy, V., Alden, D. L., Steenkamp, J. B. E. ve Ramachander, S. (2000). Effects of Brand Local and Nonlocal Origin on Consumer Attitudes in Developing Countries. Journal of Consumer Psychology, 9(2), 83-95.

Carpenter, J. M., Moore, M. ve Fairhurst, A. (2005). Consumer Shopping Value for Retail Brands. Journal of Fashion Marketing and Management, 9(1), 43-53.

Carpenter, J., Moore, M., Doherty, A. M.ve Alexander, N. (2012). Acculturation to the Global Consumer Culture: A Generational Cohort Comparison. Journal of Strategic Marketing, 20(5), 411-423.

Chen, C. F ve Chen, F. S. (2010). Experience Quality, Perceived Value, Satisfaction and Behavioral Intentions for Heritage Tourist. Tourism Management, 31, 29-35.

Chin, W., (1998). The partial least squares approach to structural equation modeling. In: Marcoulides, G.A. (Ed.). Modern Methods for Business Research, Mahwah, New Jersey: Lawrence Erlbaum Associates Publisher

Cleveland, M. ve Laroche, M. (2007). Acculturation to the Global Consumer Culture: Scale Development and Research Paradigm. Journal of Business Research, 60(3), 249-259.

Cleveland, M., Laroche, M.ve Takahashi, I. (2015). The Intersection of Global Consumer Culture and National Identity and the Effect on Japanese Consumer Behavior. Journal of International Consumer Marketing, 27(5), 364-387. 
Cleveland, M. (2018). Acculturation to the Global Consumer Culture: Ten Years After and Agenda for the Next Decade. Journal of Global Scholars of Marketing Science, 28(3), 257-271.

Durvasula, S.ve Lysonski, S. (2015). Cross-National Applicability of a Parsimonious Measure of Acculturation to Global Consumer Culture. Psychological reports, 116(3), 738-750.

Enginkaya, E. ve Ozansoy, T. (2010). Alışveriş Değeri ve Mağaza Seçim Kriterlerinin Belirlenmesinin Hazcı ve Faydacı Alışveriș Değerleri ile İlişkisi: Lise Öğrencileri Üzerine Bir Araştırma. Çukurova Üniversitesi Sosyal Bilimler Enstitüsü Dergisi, 19(1), 141-155.

Fornell, C. ve Larcker, D. (1981). Structural equation models with unobservable variables and measurement error. Journal of Marketing Research, 18(1), 39-50.

Frank P. ve Watchravesringkan K. (2016). Exploring Antecedents and Consequences of Young Consumers' Perceived Global Brand Equity. J Prod Brand Manag, 25(2), 160-169.

Ger, G. (1999). Localizing in the Global Village: Local Firms Competing in Global Markets. California Management Review, 41(4), 64-83.

Ger, G.ve Belk, R. W. (1996).I'd Like to Buy the World a Coke: Consumptionscapesof the 'Less Affluent World. Journal of Consumer Policy, 19 (3), 271-304.

Gürbüz, S. ve Şahin, F. (2014). Sosyal Bilimlerde Araştırma Yöntemleri, Ankara: Seçkin Yayıncllık.

Hair, J. F., Black, W. C., Babin, B. J., Anderson, R. E. ve Tatham, R. L. (2010). Multivariate data analysis (Seventh edition). New Jersey, Prentice Hall.

Hair, J. F., Hult, G.T.M., Ringle, C.M. \& Sarstedt, M., (2014). A primer on partial least squares structural equation modeling (PLS-SEM), SAGE Publications.

Hair, J. F., Hult., G. T. M., Ringle, C. ve Sarstedt, M. (2017). A primer on partial least squares structural equation modeling (PLS-SEM) second edition. Los Angeles: Sage.

Henseler, J., Ringle, C. M. ve Sarstedt, M. (2015). A new criterion for assessing discriminant validity in variance-based structural equation modeling. Journal of the academy of marketing science, 43(1), 115-135.

Holbrook, M. B.ve Hirschman, E. C. (1982). The Experiential Aspects of Consumption: Consumer Fantasies, Feelings, and Fun. Journal of Consumer Research, 9(2), 132-140.

Holt, D. B., Quelch, J. A.ve Taylor, E. L. (2004). How Global Brands Compete. Harvard Business Review, 82(9), 68-75.

Izberk-Bilgin, E. (2008). When Starbucks Meets Turkish Coffee: Cultural Imperialism and Islamism As 'Other' Discourses of Consumer Resistance. In A. Y. Lee, \& D. Soman, Advances in Consumer Research (Vol. 35, pp. 808-809). Duluth, MN, United States of America: Association for Consumer Research.

Jones, M.A., Reynolds, K.E. ve Arnold, M.J. (2006). Hedonic and Utilitarian Shopping Value: Investigating Differential Effects on Retail Outcomes. Journal of Business Research, 59(9), 974-981.

Keegan, W.J. ve Green M.C. (2003). Global Marketing, Upper Saddle River, NJ: Prentice Hall.

Lee, M., Kim, Y.ve Fairhurst, A. (2009). Shopping Value in Online Auctions: Their Antecedents and Outcomes. Journal of Retailing \&Consumer Services, 16(1), 75-82.

Lee, M. Y., Knight, D. ve Kim, Y. K. (2008). Brand analysis of a US global brand in comparison with domestic brands in Mexico, Korea, and Japan. Journal of Product \& Brand Management, 163174. 
Levitt, T. (1983). The Globalization of Markets. Harvard Business Review, 61 (May-June), 92-102.

Lysonski, S. ve Durvasula, S.(2013). Nigeria in transition: Acculturation to Global Consumer Culture. Journal of Consumer Marketing, 30 (6), 493-508.

Niyet, İ. Z., \& Taşpınar, O. (2020). Research on Influence of Materialism on the Consumption Habits and Perception of Coffee as Luxury Consumption. Turkish Studies-Social Sciences, 15(8), 3611-3626.

Ogden, D. T. (2002).Ethnicity and Acculturation in Consumer Purchase Decisions: TheHispanic Consumer and the United States Do-It-Yourself (DIY) Paint Segment. Ph.D.dissertation, Temple University, AAT3057104.

Okazaki, S., Taylor, C. R., Vargas, P.ve Henseler, J. (2019). Disasters, Hope and Globalization: Exploring Self-Identification with Global Consumer Culture in Japan. International Marketing Review, 36(5), 726-747.

Özcan, B. (2007). Hedonizm ve Kimlik Temeline Dayalı Postmodern Tüketim Yaklaşımı. Sosyoloji Konferansları Dergisi, (35), 139.

Özsomer, A. (2012). The Interplay Between Global and Local Brands: A Closer Look at Perceived Brand Globalness and Local Iconness. Journal of International Marketing, 20(2), 72-95.

Özsomer, A. (2019). Some Recent Influences on Global Consumer Culture. International Marketing Review, 36(4), 548-552.

Ringle., C. M., Wende S. ve Becker, J. M. (2015). SmartPLS release: 3. Germany SmartPLS GmbH: Böenningstedt

Schuh, A. (2000).Global Standardization as a Success Formula for Marketing in Central Eastern Europe?. Journal of World Business, 35(2), 133-149.

Seo, J. H.ve Huh, E. J. (2004). Cross-Cultural Comparison of Materialism and Hedonic \&Utilitarian Shopping Value: Using Korean, American, and Japanese College Students. Korean Journal of Human Ecology, 13(5), 765-776.

Sobol, K. (2008). The Global Consumer Culture: An Empirical Study in the Netherlands (Doctoral dissertation, Concordia University).

Steenkamp, J. B. E., Batra, R. ve Alden, D. L. (2003). How perceived brand globalness creates brand value. Journal of Business Studies, 1(34), 53-65.

Steenkamp, J. B. E.VeDe Jong, M. G. (2010). A Global Investigation into the Constellation of Consumer Attitudes Toward Global and Local Products. Journal of Marketing, 74(6), 18-40.

Storey, J. (2000). Popüler Kültür Çalıșmaları, Kuramlar ve Metotlar. İstanbul: Babil Yayınları.

Suprawan, L. (2018). How Young Consumers in Thailand Respond to Global Sporting Apparel Brands. Human Behavior, Development and Society, 18, 99-106.

Şengün, H.İ. ve Karahan, M. (2013). Hedonik (Hazcı) Tüketim Alışkanlıkları ve Tüketicileri Bu Tür Alışkanlıklara Motive Eden Nedenler. Dicle Üniversitesi İ̈BF Dergisi, 13-26.

Tajfel, H.ve Turner, J.(1986). The Social Identity Theory of Intergroup Behavior. In Psychological Intergroup Relations, ed. S. Worchel and W. Austin, 7-24. Chicago: Nelson-Hall.

Tomlinson, J. (1999). Globalisation and Culture. Cambridge: Polity Press.

Ural, T. (2008). Çok Uluslu İşletmelerin Tutundurma Faaliyetleri ve Kitle İletişim Araçlarının Küresel Tüketici KültürüÜzerine Etkisi. Hacettepe Üniversitesi İktisadi ve İdari Bilimler Fakültesi Dergisi, 26(2), 257-274. 
Wahyuningsih, W.ve Fatmawati, I. (2016). The Influence of Hedonic Lifestyle, Shopping Addiction, Fashion Involvement On Global Brand Impulse Buying. JBTI: Jurnal Bisnis: Teori dan Implementasi, 7(2), 278-300.

Yapraklı, T. Ş.ve Keser, E. (2016). Global Tüketici Kültürü ve Etnik Kimliğin Ürün Gruplarına Göre Tüketim Alışkanlıkları Üzerindeki Etkisi: Türkiye Uygulaması. Journal of International Social Research, 9(43).

Zhou, L., Teng, L. ve Poon, P. S. (2008). Susceptibility To Global Consumer Culture: A ThreeDimensional Scale. Psychology \&Marketing, 25(4), 336-351.

\section{Extended Abstract}

Especially in recent years, the development of technology, the increase in logistics and communication opportunities has led to the formation of a common consumption culture by increasing interaction among people around the world, and in this direction, the demand for global brands has increased. Those who adopt the aforementioned global culture at a high level have identified with the global consumer culture and have made it a kind of lifestyle. In general, in all consumption cultures, consumers can be rational and pleasure-oriented during their shopping. While the hedonic shopping value is related to the values taken from the sensory, desire and pleasure-related aspects of the consumer's shopping experience, the utilitarian shopping value is related to the rational expectations of the consumer. In this study, the simultaneous effect of "self-identification with global consumer culture" on (i) hedonic shopping value and (ii) utilitarian shopping value was examined. For this purpose, a questionnaire was applied to 302 global brand consumers, and the estimation of the structural equation model (PLS-SEM) with the Partial Least Squares method was statistically analyzed using SmartPLS 3.0 software. As a result, it was determined that self-identification with global consumer culture has a strong and positive effect on the hedonic shopping value and has a positive effect on the utilitarian shopping value.

Individuals with a high level of adopting global consumer culture have a high level of importance to materialism (Cleveland et al., 2015), the existence of positive relationships between materialism and hedonic consumption (Niyet \& Taspinar, 2020), likewise, in the hedonic framework, many consumers demand various famous or branded products that they identify with modernity in order to satisfy their expectations beyond the limits of their basic needs and, more importantly, to prove to other individuals that they are also a part of this modern world (Batra et al., 2000; Sengün and Karahan, 2013) also when it is considered that the famous brands are generally global brands; on the other hand, in the utilitarian context, considering that global brands are perceived as higher quality (Holt et al., 2004; Lee et al., 2008; Steenkamp et al., 2003); it can be stated that it is natural for individuals with a high level of "self-identification with global consumer culture" to have high hedonic and utilitarian shopping values.

The most striking result of the research is that "self-identification with global consumer culture" affects hedonic shopping value positively and strongly. Based on this finding, important inferences can be made for global businesses. It can be thought that it would be beneficial for global businesses to make their marketing plans, especially considering the hedonic shopping value of consumers. For example, planning of product designs, designs of shopping store atmospheres, advertising strategies in promotion activities, and the modern design of e-commerce site designs etc. applications can be executed to appeal to the hedonic shopping value. Considering that the other finding within the scope of the research, "self-identification with global consumer culture", affects the utilitarian shopping value positively, inferences can be made for practical applications to global businesses in the same way. Although not as much as hedonic shopping value, it is important for global businesses to consider utilitarian shopping value. It is thought that it will be beneficial to plan production processes, sales strategies and retail sales systems by considering utilitarian factors such as easy availability, quality and price of the product. Because individuals identified with the global consumer culture attach positive importance to both hedonic and utilitarian shopping values, especially hedonic shopping value. 